\title{
A LINGUAGEM E A DIMENSÃO DO CORPO NA SÍNDROME CONGÊNITA DO ZIKA VÍRUS: UM ESTUDO DE CASO
}

\author{
LANGUAGE AND BODY DIMENSION IN \\ CONGENITAL ZIKA SYNDROME (CZS): \\ A CASE STUDY
}

\author{
Carla Santos Pimentel ${ }^{\star}$ \\ Melissa Catrini** \\ Lúcia Arantes ${ }^{\star * \star}$
}

\begin{abstract}
RESUMO
Após o surto relacionado ao vírus Zika (ZIKV) no Brasil, entre os anos de 2015 e 2016, gestantes que haviam sido infectadas tiveram bebês com sequelas neurológicas importantes. Na época, foram relatados diversos casos de microcefalia associada a outras desordens neurológicas. Esse episódio se configurou como emergência em saúde pública de caráter mundial e diferentes estudos foram (e têm sido) realizados para acompanhar os bebês que haviam sido expostos a infecção congênita relacionada ao ZIKV. Essas crianças apresentam alterações neurológicas específicas, as quais são descritas na literatura como: microcefalia, desproporções craniofaciais, espasticidade, convulsões, irritabilidade, artrogripose, disfunções de tronco cerebral - disfagia e anormalidades oculares -, alterações auditivas, calcificações cerebrais, desordens corticais e ventriculomegalia. (ARAÚUJO, et. al., 2016; FRANÇA, et. al., 2016; MIRANDA, et. al.,2016; MOORE, et. al.,2017) Visto o número reduzido de estudos dedicados a linguagem nesse cenário, o objetivo da pesquisa é refletir sobre a linguagem e a dimensão do corpo em crianças com lesões neurológicas associadas a Síndrome Congênita do Zika Vírus (SCZV). A discussão tomou como referência o momento em que essas crianças começam a frequentar o espaço escolar. Assim, a partir do recorte metodológico de estudo de caso e da observação participante, foram realizadas filmagens de situações dialógicas, ocorridas no ambiente escolar, entre uma criança diagnosticada com a SCZV e seus colegas, professores, a Auxiliar de Desenvolvimento Infantil e uma pesquisadora. Como resultado, evidenciamos a presença de um corpo que, mesmo submetido às limitações impostas pela lesão orgânica, fazia presença no diálogo pedindo por interpretação. A técnica da observação participante possibilitou que essa presença pudesse ser reconhecida no espaço escolar, o que nos mostra a maneira pela qual o encontro interprofissional pode produzir deslocamentos que levem um profissional da educação a ocupar uma posição que dê condições para mudanças serem operadas na relação da criança com a linguagem e com o grupo.
\end{abstract}

Palavras-chaves: linguagem, corpo, zika, interprofissionalidade, fonoaudiologia

\section{ABSTRACT}

After the outbreak related to the Zika virus (ZIKV) in Brazil, between the years 2015 and 2016, pregnant women who had been infected had babies with important neurological sequelae. At the time, several cases of microcephaly associated with other neurological disorders were reported. This episode was configured as a worldwide public health emergency and different studies were (and have been) carried out to monitor babies who had been exposed to congenital ZIKV infection. These children have specific neurological disorders, which are described in the literature as microcephaly, craniofacial disproportions, spasticity, seizures, irritability, arthrogryposis, brainstem dysfunctions - dysphagia and eye abnormalities -, hearing disorders, brain calcifications, cortical disorders, and ventriculomegaly. (ARAÚJO, et. al., 2016; FRANCE, et. al., 2016; MIRANDA, et. al., 2016; MOORE, et. al., 2017) Given the small number of studies dedicated to language in this scenario, the objective of the research is to reflect on language and body dimension in children with neurological injuries associated with Congenital Zika Syndrome (CZS). The discussion took as a reference the moment when these children begin to attend school. Thus, based on the methodological approach of the case study and participant observation, filming of dialogic situations, which occurred in the school environment, was filmed between a child diagnosed with CZS and his colleagues, teachers, the Child Development Assistant, and a researcher. As a result, we evidenced the presence of a body that, even submitted to the limitations imposed by the organic injury, was present in the dialogue asking for interpretation. The participant observation technique allowed this presence to be recognized in the school space, which shows us how the interprofessional meeting can produce displacements

* Pós graduada pelo programa de Residência Multiprofissional em Saúde Coletiva da Universidade Federal da Bahia (UFBA), Salvador, BA, Brasil.cspimentel.fono@gmail.com

Orcid: https://orcid.org/0000-0001-8632-306X

** Universidade Federal da Bahia (UFBA), Salvador, BA, Brasil. melissa.catrini@ufba.br Orcid: https://orcid.org/0000-0002-2947-3157

***Pontifícia Universidade Católica de São Paulo (PUCSP), São Paulo, SP, Brasil. loureiroarant@uol.com.br Orcid: https://orcid.org/0000-0001-5982-1100 
that lead an education professional to occupy a position that allows conditions for changes to be operated in the relationship of the child with language and with the group.

Keywords: language, body, Zika, interprofessional, speech therapy

\section{INTRODUÇÃO E REVISÃO DE LITERATURA}

Em 2015, um surto relacionado ao vírus Zika (ZIKV) atingiu um número expressivo de gestantes no nordeste brasileiro', as quais, ao serem infectadas, tiverem bebês com sequelas neurológicas importantes. À época, foram relatados diversos casos de nascimentos de bebês com microcefalia associada a outras desordens neurológicas. (COSTELLO, et. al., 2016) Esses bebês, com a infecção congênita relacionada ao ZIKV, têm seu desenvolvimento marcado por alterações neurológicas específicas, descritas na literatura como microcefalia, desproporções craniofaciais, espasticidade, convulsões, irritabilidade, artrogripose, disfunções de tronco cerebral - com disfagia e anormalidades oculares -, alterações auditivas, calcificações cerebrais, desordens corticais e ventriculomegalia. (ARAÚJO, et. al., 2016; FRANÇA, et. al., 2016; MIRANDA, et. al.,2016; MOORE, et. al., 2017).

Estudos recentes apontam que a Paralisia Cerebral (PC) faz parte do amplo espectro da Síndrome Congênita do Zika Vírus (SCZV) (MOORE, et. al., 2017) e a sua associação está relacionada com os casos mais graves da síndrome, causando importante prejuízo neurodesenvolvimental. (CARVALHO, et. al., 2019) A paralisia cerebral é descrita na literatura como uma desordem permanente no movimento e na postura corporal, sendo caracterizada como encefalopatia crônica não progressiva. O diagnóstico baseia-se em sinais clínicos e os dados indicam que este diagnóstico pode ser feito até os 12 meses de vida. (ROSENBAUM, et. al., 2006) Vale destacar que por se tratar de uma condição neurológica recentemente descrita na literatura, ainda são escassas as publicações referentes ao desenvolvimento neuropsicomotor das crianças acometidas pela SCZV. O que se pode dizer até o momento é que essas crianças apresentam características específicas e distintas de outros quadros que envolvem encefalopatias crônicas não progressivas.

O desenvolvimento das crianças acometidas pelo ZIKV tem sido acompanhado por pesquisadores a partir da aplicação de protocolos/teste de rastreio, a partir de análises descritivas e de natureza quantitativa. Alves et. al. (2018) avaliaram o desenvolvimento neurológico de 24 crianças com a SCZV, entre 18 e 24 meses. Os pesquisadores utilizaram o Teste Denver II - Teste de triagem do desenvolvimento (FRANKENBURG, et. al., 1992), para a avaliação dos seguintes aspectos: motor fino, motor grosso, linguagem e psicossocial. Os resultados demonstraram uma grande discrepância entre a idade cronológica e a idade desenvolvimental obtida no teste. No que concerne à linguagem, foram observadas a produção de som, a habilidade de reconhecimento, compreensão e uso da linguagem. As crianças obtiveram resultados muito abaixo do esperado. No estudo, a idade cronológica média ao exame clínico foi de 19,9 meses e a idade equivalente para linguagem foi de 2,1 meses.

Wheeler et. al. (2018) realizaram um estudo piloto com 47 crianças com a SCZV, entre 13 e 22 meses, acompanhados no Centro Especializado em Reabilitação 'Menina dos Olhos' (CER IV), localizado em Recife. Foram coletados relatos dos pais sobre o desenvolvimento da criança e o sono, e para a avaliação específica foram utilizados os protocolos Ages and Stages Questionnaire (3a edição) (SQUIRES, et. al., 2009) e Brief Infant Sleep Questionnaire (NUNES, KAMPFF, SADEH, 2012). Em relação à comunicação, os autores referem que a maioria das crianças se comunicaram utilizando sons e gritos $(72 \%)$, e barulhos ${ }^{2}$ durante a brincadeira (77\%). Grande parte das crianças reagiu aos sons a sua volta e atendeu ao ouvir a voz dos seus cuidadores (72\%), procurou a direção dos sons (83\%) e compreendeu o "não" (57\%), mas apenas 1/4 das crianças envolvidas em situação lúdica apresentaram interação utilizando vocalizações.

Carvalho et. al. (2019) realizaram um estudo para a avaliação clínica e do neurodesenvolvimento de 82 crianças com Paralisia Cerebral e provável infecção congênita do Zika vírus. Para a avaliação do desenvolvimento, os pesquisadores aplicaram o protocolo Bayley III - escala de teste do desenvolvimento infantil. (BAYLEY, 2006) No que diz respeito à linguagem, os resultados obtidos revelaram respostas muito abaixo do esperado pela linha referência do protocolo, sendo que $97.6 \%$ (80) das crianças apresentaram scores extremamente baixos e $2.4 \%$ (2) das crianças apresentaram score abaixo do esperado.

1. Entre as semanas epidemiológicas 45/2015 e 40/2019 do Boletim Epidemiológico, divulgado pelo Ministério da Saúde, foram notificados 10.403 casos suspeitos de crianças com alterações no crescimento e desenvolvimento possivelmente relacionados à infecção pelo vírus Zika na região nordeste do Brasil. Ao final foram confirmados 2.179 casos. (BRASIL, 2019)

2. Os autores não especificaram na pesquisa o que foi denominado de "barulho". 
É digno de nota que as pesquisas realizadas até o momento tenham incluído no acompanhamento de crianças com SCZV observações a respeito do desenvolvimento da linguagem. Os estudos, no entanto, destacam o forte impedimento na expressão oral dessas crianças, o que é demonstrado pelo registro da diminuição dos scores das respostas quando aplicados itens dos protocolos relacionados à linguagem. Deve-se dizer que, em sua maioria, esses instrumentos de rastreio privilegiam os aspectos relacionados à oralidade. De maneira clara, esses estudos operam a redução da linguagem à ideia de comunicação e analisam a performance infantil em comparação a um padrão de referência ideal.

Arantes $(2001,2005,2006,2009)$ coloca em discussão o uso irrestrito de protocolos/testes padronizados na avaliação de linguagem operacionalizada no campo da Fonoaudiologia. A autora destaca o caráter meramente descritivo da aplicação de instrumental linguístico sobre a fala sintomática de crianças, o que seria um reflexo do que denominou, com Lier-DeVitto (2005), de "(mau)encontro" da Fonoaudiologia com a Linguística. A natureza desse "mau encontro", destaca a autora, ilumina o fato de que no gesto de aplicação o fonoaudiólogo "perde de vista" seu principal compromisso no espaço clínico, que deveria ser com a fala da criança.

Pode-se dizer que, historicamente, a Fonoaudiologia tem buscado como referência estudos de aquisição de linguagem como linha basal para a partição normal/patológico e, nesse passo, tem se alinhado à concepção de linguagem como objeto de conbecimento parcelável, subordinada a estágios desenvolvimentais de apreensão do código linguístico ou, dito de outro modo, sujeito às condições orgânico-mentais e ambientais compreendidas como necessárias para seu aprendizado/apropriação pela criança. (LEMOS, 2006) Nesse cenário, os efeitos da SCZV ainda não foram explorados no meio científico de maneira a ultrapassar a mera constatação do déficit, o que dificulta que se retirem consequências éticas para o cuidado dessas crianças.

Impera em tais estudos uma perspectiva biomédica, que apaga a complexidade envolvida no entendimento da noção de deficiência e da pluralidade de seus efeitos. Deve-se assinalar que o modelo biomédico assume uma concepção de deficiência na qual o corpo deficiente é delineado a partir de uma representação do que seria o corpo sem deficiência. Sob esse ponto de vista, "ser deficiente é experimentar um corpo fora da norma", anormal segundo "um julgamento estético e, portanto, um valor moral sobre os estilos de vida". (DINIZ, 2007, p.4) Mais do que isso, o corpo deficiente é signo de patologia, incapacidade e desvantagem. Alinhados a essa lógica, os estudos realizados até o momento objetivam analisar "habilidades" adquiridas e observar atrasos em relação a estágios desenvolvimentais previamente estabelecidos. Obviamente, os impedimentos impostos pela perturbação do funcionamento orgânico e a importância dada para a oralidade acabam por aprisionar pesquisadores e clínicos na contabilização do déficit, provocando o apagamento da heterogeneidade e singularidade dos acontecimentos linguísticos e da complexidade inerente à relação entre corpo e linguagem ${ }^{3}$.

Lemos (2006) chama atenção para a impossibilidade de se conceber a linguagem como objeto de conhecimento e a aquisição como processo de aprendizagem/construção. A autora apresenta argumentos teórico-empíricos que nos alertam para o fato de que os estudos em aquisição de linguagem não puderam estabelecer a ordem de formação e emergência das unidades linguísticas. Por um lado, afirma Lemos, as propriedades das entidades linguísticas são interdependentes do ponto de vista morfossintático, semântico e fonológico. De outro lado, os achados empíricos das pesquisas demonstraram que a fala da criança é imprevisível do ponto de vista linguístico (enunciados fragmentados, certos e errados, convivem num mesmo período de tempo) e que mesmo assim falantes se dirigem a elas e as interpretam como falantes de sua língua.

Diante disso, Lemos elege e verticaliza a teorização sobre a questão da mudança na aquisição de linguagem, enfatizando que a fala inicial da criança mostra a relação desta com a linguagem, ainda que não se possa tomar tal relação como a construção de conhecimento. Como assinalam Lier-DeVitto e Arantes (2020, p. 68), Lemos

opõe-se tanto às visões empiristas inspiradas na Psicologia quanto ao inatismo de Chomsky [e, ao se aproximar do trabalho de Saussure, atribui ao termo Interacionismo um sentido particular], qual seja, o de 'interação/relação' triádica. O outro vem como instância do funcionamento da língua (LEMOS, 1992) - como 'falante', já que o que importa é sua fala em que nela a língua se movimenta.

3. Há outras possibilidades de compreensão da deficiência, as quais têm origem em estudos que a incluem no campo das humanidades, ultrapassam a ideia de déficit e vão na direção de uma "discursividade positiva" em que a deficiência é "um conceito complexo que reconhece o corpo com lesão, mas que também denuncia a estrutura social que oprime a pessoa deficiente". (DINIZ, 2007, p.4) Nesse caminho, a deficiência reflete modos corporais de estar no mundo, o que desafia padrões de normalidade e anormalidade definidos pelo ponto de vista biomédico. 
A referência a concepção saussuriana de Língua, enquanto funcionamento e sistema, afasta o Interacionismo em Aquisição de Linguagem proposto por Lemos do pensamento gramatical e desenvolvimentista, abrindo a possibilidade de uma via alternativa de abordagem da fala e do corpo que fala. O modelo teórico proposto pela autora parte da proposição saussuriana de que a Língua é um funcionamento estrutural e que, portanto, tem anterioridade lógica em relação ao sujeito. Em sua teorização, a aquisição de linguagem é definida como processo de subjetivação em que são operadas mudanças de posição da criança frente à fala do outro, à Língua e à própria fala. Processo esse, nas palavras de Lemos (2006, p. 28), "[indissociavelmente relacionado] a um corpo pulsional, i.e, à criança como corpo cuja atividade demanda interpretação".

A concepção de corpo assumida deriva do diálogo teórico entre a linguística e a psicanálise, isto é, o corpo é referenciado a partir de uma teoria de linguagem afetada pelo fato de haver sujeito na língua. Nessa direção,

parte-se da premissa de que o sujeito é efeito da linguagem, ao tempo em que a própria linguagem não pode ser concebida como deslocada/fora do sujeito. O eixo da teoria remete, assim, a articulação entre língua-fala-falante. Aqui a concepção de corpo ultrapassa a lógica orgânica e a relação sujeito-objeto é invertida, uma vez que se concebe "a criança como capturada por um funcionamento linguístico-discursivo que não só a significa como lhe permite significar outra coisa, para além do que a significou" (DE LEMOS, 2002, p.55). (OLIVEIRA e CATRINI, 2017, p. 375)

Vale lembrar que na abordagem inatista em aquisição de linguagem o linguístico é compreendido como um estado cerebral/mental. Já em abordagens interacionistas ligadas à psicologia do desenvolvimento, a relação entre corpo e linguagem é de natureza dialética, ou seja, à medida que o organismo se apropria do conhecimento linguístico é por ele transformado. Essa leitura, entretanto, não se desvencilha da noção de desenvolvimento, o que impede a observação da heterogeneidade e singularidade da fala da criança. (OLIVEIRA e CATRINI, 2017; LIER-DEVITTO e ARANTES, 2020)

Frente aos argumentos até aqui apresentados, podemos dizer que a SCZV remete diretamente ao enlaçamento entre corpo e linguagem e, portanto, ao lugar de onde incide o ponto de vista do investigador na leitura dos acontecimentos a serem interpretados. A complexidade envolvida nessa relação reitera a importância de que outros estudos sejam realizados, e, principalmente, no que concerne às avalições de linguagem, que se possa considerar a heterogeneidade e singularidade das manifestações sintomáticas de linguagem presentes nestes sujeitos. O ponto é compreender a relação da criança com a linguagem, bem como a implicação dos impedimentos orgânicos severos sobre o modo pelo qual o outro-falante pode, ou não, reconhecer no corpo prejudicado uma exigência de interpretação para além do reconhecimento de características da doença. (SANTOS, CATRINI e FERRITE, 2018) Nessa direção, os estudos conduzidos por pesquisadores vinculados ao Grupo de Pesquisa CNPq "Aquisição, Patologias e Clínica de Linguagem" (LAEL/PUC-SP) nos apresentam um novo horizonte de investigação, pois demonstram que a incidência da linguagem sobre o corpo promove um "transbordamento" de limites/restrições mesmo quando lesões neurológicas impõem impasses à entrada da criança na linguagem. (CATRINI e LIER-DEVITTO, 2019; VASCONCELLOS, 2018; DUDAS, 2009)

Ressalta-se que recentemente as crianças acometidas pelo vírus Zika completaram 4 anos de idade e que, além da demanda por cuidado especializado ser contínua, muitas delas estão vivenciando seus primeiros momentos na rotina escolar. Tendo em vista o número reduzido de estudos qualitativos que possam dar subsídios para se discutir a dimensão do corpo e a linguagem no contexto da SCZV, o presente trabalho tem como objetivo refletir sobre a linguagem e a dimensão do corpo em crianças com lesões neurológicas associadas a SCZV, tomando como referência o momento em que essas crianças começam a frequentar o espaço escolar. Assim, a partir do recorte metodológico de estudo de caso e da observação participante, este estudo coloca em análise situações dialógicas da criança com os colegas, profissionais da educação e uma fonoaudióloga, pesquisadora responsável pela coleta dos dados.

\section{METODOLOGIA}

Trata-se de um estudo de caso de caráter qualitativo, transversal e exploratório, que buscou refletir sobre a dimensão do corpo na aquisição de linguagem a partir da análise de situações dialógicas entre crianças com leões neurológicas associadas à SCZV e o outro/cuidador/professor/pesquisador no contexto escolar. A escolha pela metodologia de estudo de caso tem relação com a importância desse tipo de investigação na apreensão do modo como a interpretação que o outro oferece para a criança produz efeitos sobre ela e sua entrada na linguagem. Isso 
porque permite abarcar inquietações e impasses relativos aos múltiplos efeitos de uma vivência singular e a partir daí desdobrar questões de natureza teórica. (NASIO, 2001)

O estudo foi realizado em uma "creche e pré-escola municipal", localizada no município de Salvador. Esse espaço foi escolhido por ser um local onde há uma grande concentração de crianças com a SCZV. Para inclusão de participantes no estudo foram estabelecidos os seguintes critérios: I) idade entre 3 e 4 anos; II) presença de lesão neurológica decorrente da SCZV; III) assiduidade no espaço escolar selecionado; IV) crianças cujo cuidador principal e profissionais da educação a ela relacionados (professoras e auxiliar de desenvolvimento infantil - ADI) aceitaram a participação no estudo mediante assinatura do Termo de Consentimento para Uso de Imagem e Som da Voz (TCUISV). Foram excluídas do estudo as crianças que não apresentavam lesão neurológica decorrente da SCZV e cuja frequência escolar era abaixo de $75 \%$.

Inicialmente, oito (8) crianças foram selecionadas. No entanto, tendo em vista que apenas uma delas apresentava assiduidade nas atividades escolares, o presente estudo se tornou um estudo de caso único. No total, 3 sujeitos participaram da pesquisa: uma (1) criança com a SCZV, uma (1) professora e uma (1) ADI - profissionais que atuavam diretamente junto à criança selecionada. Vale destacar que o lócus desse estudo também era o campo de atuação de residentes de um Programa de Residência Multiprofissional em Saúde Coletiva com ênfase na primeira infância, sendo um espaço prévio de inserção da pesquisadora principal da pesquisa enquanto fonoaudióloga residente atuante em ações de promoção do desenvolvimento infantil. Nesse cenário, foi possível a utilização da técnica de observação participante para a geração de dados (MINAYO, 2014), pois a frequente presença da pesquisadora possibilitou sua inserção em situações específicas, nas quais ela pôde modificar e ser modificada por esse contexto social. (SCHWARTZ; SCHWARTZ, 1955 apud MINAYO, 2014, p. 273-274)

Ao longo de seis semanas consecutivas, com a frequência de dois turnos semanais, situações dialógicas que ocorriam em atividades da rotina escolar da criança foram filmadas. Para a gravação, foram escolhidas as rotinas diárias que mais promoviam a interação, sendo utilizada uma Câmera Digital (Canon EOS DSL2 24MP), posicionada estrategicamente com o propósito de observar as situações dialógicas 'in loco' entre a criança e o outro. As filmagens ocorreram concomitantemente ao registro de impressões da pesquisadora em diário de campo e as cenas dialógicas gravadas foram transcritas ortograficamente.

Ao todo, foram obtidas aproximadamente 4 horas e 10 minutos de filmagem da criança em situações dialógicas com a professora, a ADI e a pesquisadora. Inicialmente, fazia parte da proposta a realização de entrevista com o cuidador principal. O objetivo era compreender a relação entre cuidador e criança, e seus efeitos sobre trajetória da criança na aquisição de linguagem. Entretanto, esse passo não pôde ser dado porque a cuidadora principal não se sentiu confortável em ser entrevistada em mais uma pesquisa científica. De fato, vários estudos vêm sendo empreendidos com a população de crianças com SCZV e seus famílias. Embora houvesse consentimento para a participação da criança e para as filmagens, a cuidadora principal - no caso, a mãe da criança, preferiu manter-se afastada.

Quanto às filmagens, algumas limitações foram observadas, dentre as quais destacam-se: a rotina da creche, com maior tempo dedicado ao cuidado das crianças (momento do banho, da alimentação e do sono), e a curiosidade das demais crianças, que se mostravam desejosas de também serem filmadas e/ou fotografadas.

Este trabalho foi submetido ao comitê de ética em pesquisa do Instituto de Saúde Coletiva (ISC/UFBA), sendo aprovado sob o parecer CAAE n ${ }^{\circ}$ 17503419.6.0000.5030, bem como autorizado pela Secretaria Municipal de Educação da cidade de Salvador (SMED).

\subsection{Análise dos dados}

Inicialmente, as gravações foram assistidas na íntegra e as cenas foram descritas de maneira narrativa. Num momento posterior, foram estabelecidos recortes dos momentos em que a criança era convocada para o diálogo e/ ou tinha a iniciativa para o diálogo. A partir daí, as filmagens foram retomadas e transcrições ortográficas das cenas selecionadas foram realizadas. A análise das transcrições seguiu o princípio da leitura flutuante, tal como propôs Carvalho (2006), e teve como referência os instrumentos teóricos postulados pelo Interacionismo em Aquisição de Linguagem (LEMOS, 1992, 2002, 2006) e pelas elaborações teórico-clínicas que subjazem a insígnia "Clínica de 
Linguagem", tal qual proposta pelo grupo pesquisa mencionado na introdução do trabalho, o qual é coordenado por Lier-DeVitto e Catrini, no LAEL/PUCSP4.

Em resumo, o intuito foi observar: 1) o modo como a fala da criança comparece, entendendo "fala" como a face da execução da linguagem que pode se presentificar por diferentes vias corporais (SAUSSURE, 1916); 2) o modo como o outro escuta e interpreta esse corpo, buscando apreender qual a relação que ele entretém com a fala da criança e, por último, 3) a relação que a criança entretém com a fala do outro. Dizendo em outras palavras, o roteiro de análise foi norteado por três perguntas: Como a fala da criança se compõe? Qual a relação que o outro entretém com o modo de presença do corpo e da fala da criança? Qual a relação que a criança entretém com a fala que lhe é dirigida?

Note-se que a análise esteve pautada no conceito de escuta, ancorada na "Clínica de Linguagem" que, em diálogo com o Interacionismo em Aquisição de Linguagem e a Psicanálise, aponta para a complexidade envolvida na relação sujeito-língua-fala. Sob essa perspectiva, Andrade $(2003$, 2005) destaca a diferença entre ouvir e escutar, enfatizando que o primeiro está relacionado a uma condição do aparato orgânico (perceptual) e o segundo está imbricado aos efeitos provocados pela fala no sujeito. A autora assinala como diretriz para a abordagem da fala o distanciamento da esfera perceptual e a aproximação ao modo singular e heterogêneo da relação do sujeito com as manifestações linguísticas. Segundo Lier-DeVitto e Emendabili (2015), Andrade aponta para a necessária inclusão do linguístico na explicação do de problemas na fala. Isso porque, escutar diz respeito ao modo pelo qual a fala é atravessada pelo funcionamento da língua, o que possibilita a emergência do sujeito. Escutar, assim, "é efeito que decorre da estruturação do sujeito pela linguagem", sendo por isso que "quando há escuta para a fala pode-se dizer que há indícios da presença de um sujeito (mesmo que a fala não se apresente)" (p.77). Não é sem razão que Carvalho (2017) aponta para a necessidade de o investigador deixar-se surpreender pela fala da criança e que ele possa ser capturado pelo jogo de ressonâncias entre as falas na cena dialógica. Foi esse o direcionamento dado na presente pesquisa.

\section{RESULTADOS}

C., 4 anos, é um menino muito sorridente, assíduo no âmbito escolar e participativo nas atividades desenvolvidas em sala de aula. Com sorologias positivas para infecção pelo vírus Zika, C. apresenta calcificações corticais compatíveis com a paralisia cerebral - condição neurológica que impôs limitações motoras em membros inferiores e superiores, com maior mobilidade do braço esquerdo e restrições de amplitude do movimento do braço direito, dificultando o exercício da motricidade fina. C. faz uso de cadeira de rodas adaptada. No que concerne à alimentação, segue dieta restrita devido à intolerância a lactose, embora apresente deglutição funcional sem restrições quanto à consistência e sem episódios de internações por pneumonias aspirativas. Cabe ressaltar que a criança apresenta sialorreia em repouso e não se alimenta de maneira independente, sendo necessário o auxílio de um cuidador. Quanto à linguagem, a principal observação era a ausência de oralidade.

A criança mora com os pais e é filho único, residindo em um bairro afastado do centro da cidade de Salvador. Faz acompanhamentos terapêuticos na rede especializada com equipe multidisciplinar em uma Organização Não Governamental-ONG (fisioterapia, fonoaudiologia e terapia ocupacional). Frequenta a equoterapia e é acompanhado por neurologista. Até o final dessa pesquisa, a mãe da criança não estava trabalhando formalmente e C. não havia completado um ano na creche, onde fazia parte de um grupo em que quatro das 18 crianças tinham o diagnóstico da SCZV. Todas as crianças do grupo tinham em torno de quatro anos de idade. Dentre as crianças diagnosticadas, C. era o único que tinha assiduidade no espaço escolar e acompanhava as atividades de rotina da creche.

Essas atividades eram desempenhadas de maneira grupal (assistir a desenhos e cantar músicas infantis) ou individual (brincadeira livre e desenho), dependendo dos objetivos pedagógicos propostos para o dia. Em geral, por ser uma creche, entre uma atividade e outra, as crianças se alimentavam, bem como havia um espaço para realizar cuidados com a higiene. Todos os dias, após o almoço, eram disponibilizadas aproximadamente 2 horas para que elas pudessem dormir.

4. Deve-se dizer que o referido grupo de pesquisa tem braços atuantes na Universidade Estadual do Centro-Oeste, com a Profa. Juliana Marcolino-Galli, na Universidade Católica de Pernambuco, com a Profa. Glória Carvalho, e na Universidade Federal da Bahia, com a Profa. Melissa Catrini da Silva. 
Ao iniciar a coleta dos dados, a pesquisadora já era figura presente no cotidiano da escola, como membro da equipe Residência Multiprofissional que lá atuava em ações para promoção do desenvolvimento infantil junto aos familiares das crianças. Apesar de sua presença constante, deve-se dizer, as crianças ficaram extasiadas com a presença mais próxima da pesquisadora e com os equipamentos de filmagem. Ressalta-se que, no primeiro dia, C. sorria bastante e olhava para a câmera ao perceber que estava sendo filmado, comportamento igual ao das outras crianças de seu grupo.

As primeiras impressões da pesquisadora sobre o modo de presença de C. nas atividades de rotina da creche foram registras no diário de campo. Cabe destacar, no entanto, que, por coincidência, o primeiro contato da pesquisadora com a criança se deu fora do ambiente escolar, em uma Unidade de Saúde da Família (USF) de Salvador. Nesse encontro, a pesquisadora já havia notado a presença de uma criança alegre e sorridente, que realizava contato visual e convocava a todo o momento o outro. Características também descritas no diário de campo da pesquisa. C. era sorridente, atento e acompanhava as atividades que eram solicitadas pela professora, apesar das dificuldades em atividades que exigiam o exercício da motricidade fina.

Os colegas de classe de C. demonstravam carinho e cuidado com ele. Em diversos momentos, realizavam tentativas de interação e inclusão durante as brincadeiras livres. Era recorrente, no entanto, que as crianças se referissem a C. como se sua condição fosse a de um bebê. Era comum que se falasse sobre ele como se não estivesse presente ou como se não pudesse compreender o que estava se passando. Em um determinado momento, enquanto C. manipulava o crachá da pesquisadora, uma das crianças observando a cena disse: "ele gosta, ele gosta porque é bebê". Surpresa, a pesquisadora perguntou: "bebê?". Foi quando a professora se aproximou e disse: "por mais que a gente fale que não é bebê, eles só acham que $\mathrm{C}$. é bebê. E a gente todo dia fala que ele não é bebê, que ele tem a mesma idade. Fiz uma aula até falando justamente da idade, mas para eles...".

Deve-se dizer que as anotações de campo trazem elementos que reafirmam em ações o lugar em que C. é colocado pelas crianças. C. era todo o tempo acompanhado por uma auxiliar de desenvolvimento infantil (ADI), usava fraldas e precisava ser alimentado. Cuidados que, na creche, eram direcionados às crianças menores. Outro aspecto a ser mencionado é que a troca de fraldas era realizada na sala de aula, sob os olhares dos colegas de classe. Nesses momentos, a pesquisadora constatou maior movimentação corporal de C., o que parecia denotar seu incômodo/ insatisfação com a situação. Além disso, durante a brincadeira livre, alguns brinquedos eram de uso exclusivo de C., sendo eles bonecos de pelúcia e brinquedos similares aos oferecidos aos bebês.

Durante a geração de dados em campo, a pesquisadora observou, ainda, que era comum a utilização do termo "Portador de Necessidades Especiais" e notou que essa expressão estava grafada nas portas dos banheiros adaptados. Com relação a isso, chamou atenção um diálogo entre a professora e uma das crianças do grupo, o qual foi registrado em diário de campo. Ao tentar explicar para a criança que C. não era um bebê, a professora mencionou que ele era uma criança "especial". Como resposta, o aluno disse sem titubear: "eu também sou especial". De fato, parece que nesse cenário pouco importava a idade cronológica de C., uma vez que a ausência de oralidade e a demanda por atenção específica afetavam o modo como as relações entre ele, as profissionais de educação e as outras crianças eram estabelecidas.

Durante as filmagens, a professora relatou dificuldades em avaliar o desenvolvimento pedagógico de C., especialmente seu conhecimento sobre cores, formas, letras e números, pois a criança não "falava". Inspirada nos diferentes sistemas de comunicação suplementar e alternativa (CSA), a pesquisadora sugeriu que se construísse uma situação em que perguntas relacionadas aos conteúdos pedagógicos fossem dirigidas à criança e que ela pudesse usar o gesto de apontar como forma de resposta. Com o uso dos princípios da CSA, observou-se uma resposta satisfatória da criança, o que surpreendeu a professora. Na cena em questão, apresentada a seguir, a criança escuta a fala que lhe é dirigida e responde ao que foi perguntado da maneira esperada.

\section{Cena enunciativa 1}

As crianças estão sentadas em um semicírculo, conhecido como "rodinha", com a professora ao centro. C. está sentado em uma cadeira adaptada ao lado da professora (A1).

(1) A1: C. olha aqui, qual é o vermelho? (A professora pega duas garrafas coloridas, uma amarela, posicionada no lado direito de C., e outra vermelha, posicionada no lado esquerdo) 
(2) C: (olha e aponta para garrafa vermelha com a mão esquerda)

(3) A1: (olha para C., sorri e olha para a pesquisadora)

(4) C: (sorri, continua apontando e tenta segurar a garrafa vermelha)

(5) A1: Pronto, segure o vermelho, vou botar aqui, vou botar aqui, pronto (coloca a garrafa vermelha no chão)

(6) C: (observa a professora colocar a garrafa no chão)

(7) A1: Qual é o azul? (com a garrafa amarela posicionada no lado direito de C. e a garrafa azul posicionada no lado esquerdo)

(8) C: (olha e emite sons ininteligíveis)

A escuta e o modo de interpretação que o outro ofertava a C., por vezes, realizava apagamentos de sua subjetividade e potencialidade para as situações dialógicas, como se ali não houvesse um sujeito que pudesse dirigir ao outro demanda alguma. Com a intervenção da pesquisadora, as pessoas que estavam ao redor de C. passaram a se relacionar de outras formas com a criança, dando-lhe possibilidades de respostas que não somente pela oralidade, passando a apostar/investir em sua capacidade de estar e falar com o outro. Na cena acima, é possível notar que o modo de comparecimento da fala de C. é marcado no corpo sob diversas formas, seja pelo olhar, sorrisos, gestos indicativos e emissões sonoras (mais adiante, veremos que o toque no corpo do outro e breves momentos de oralidade também entram nessa lista). Essas falas surgem em resposta ao outro mediante a escuta aberta ao diálogo com a criança. É preciso abrir a escuta para o corpo que fala.

Inicialmente, percebeu-se que a criança se posicionava mais como observador das cenas, cumprindo atividades escolares, mas respondendo quando solicitado.

\section{Cena enunciativa 2:}

C. está sentado à mesa, sobre a qual estão dispostos brinquedos de encaixe e um boneco de pelúcia do personagem Scooby-Doo (objeto de uso exclusivo da criança). A pesquisadora (P.) se aproxima de C., que está tentando encaixar um cubo verde em uma peça de brinquedo em formato de haste.

(9) P: virou picolé foi?

(10) C: (aproxima o objeto montado à boca)

(11) P: é picolé? (observando a criança)

(12) C: (afasta o objeto da boca, olha, sorri e aproxima o objeto da boca da pesquisadora)

(13) P: é picolé? (olhando para a criança)

(14) C: (permanece olhando para a pesquisadora)

(15) P: (segura o objeto e faz como se "lambesse um picolé")

(16) C: (observa a pesquisadora)

(17) P: huuuum, picolé.

(18) C: (sorri e afasta o objeto da boca da pesquisadora)

(19) P: (observa a criança)

(20) C: (sorrindo, aproxima o objeto à colega que está ao seu lado)

(21) P: olha o picolé que C. fez (tocando o braço da criança)

(22) C: (observa o colega segurando o objeto montado)

C. estava entretido na tarefa que lhe foi designada pela rotina escolar (momento de brincadeira livre e exercício da motricidade fina e grossa com peças de encaixe). Estava completamente absorto na tentativa de ultrapassar uma motricidade errante, quando recebe o convite da pesquisadora para um jogo de natureza bem diferente. Um cubo encaixado sobre uma haste torna-se um picolé. Segue daí um convite ao diálogo que vem em forma de pergunta: (9) "virou picolé foi?", diz a pesquisadora. Dada a impossibilidade de oferecer uma resposta oral ou fala oralizada, levar o objeto em direção à boca foi interpretado como o significante picolé: (11) "é picolé é?". O retorno desse gesto, como em (10), (12) e (18), somado aos olhares e sorrisos dirigidos à pesquisadora em (12), (18) e (20), permitiram a sustentação de tal interpretação e indiciaram para a pesquisadora que ali havia escuta para a fala do outro e, até mesmo, o esboço de uma atividade simbólica. 
Deve-se destacar, ainda, o momento em que a pesquisadora empresta a sua voz e lê o gesto de C. quando este aproxima o objeto de um colega ao lado (ver em 20 e 21). Ainda que o desfecho da cena mostre C. em posição de observador (ver em 22), a interpretação oferecida acaba por deslocá-lo para uma posição mais ativa, como aquele que convoca o outro a brincar. Abaixo, pode-se observar como a incidência da interpretação da pesquisadora sobre o corpo da criança sustenta o diálogo e mobiliza os outros profissionais a compartilharem desse espaço.

\section{Cena enunciativa 3:}

C. está sentado à mesa junto com os colegas. Todas as crianças continuam com brinquedos em mãos antes da professora iniciar a atividade do dia. (Abaixo temos: C. criança, P. pesquisadora, A1 auxiliar de desenvolvimento infantil - ADI).

(22) C: (continua brincando com as peças, pega um brinquedo montado, aproxima do ouvido e sorri)

(23) P: alô? ( ) É telefone?

(24) C: (olha para a peça montada, olha a pesquisadora e aproxima novamente o objeto do ouvido, sorrindo)

(25) P: alô? Quem é que tá falando?

(26) C: (sorri e coloca a peça montada em cima da mesa)

(27) A1: C., cadê o telefone C.?

(28) C: (aproxima duas peças do ouvido, sorrindo)

(29) A1: fala aí, alô, C.

(30) C: (está brincando com os colegas)

(31) A1: fala aí, alô

(32) C: (pega outra peça em cima da mesa e aproxima do ouvido, sorrindo)

(33) A1: fala aí alô

(34) P: alô, eita o telefone caiu!

(35) A1: (ajuda a pegar as peças que caíram no chão)

(36) C: (volta a brincar com as peças de brinquedo dispostas na mesa)

Note-se que A1 busca sustentar a brincadeira, mas C. não pode responder ao apelo pela oralidade ("fala aí alô"') e logo dispersa. Nesse sentido, é importante remeter ao dado registrado em diário de campo. Apesar de atento e disposto ao contato com o outro, é também característica de C. a dispersão. Como se pode ver na cena descrita acima, a criança se liga à fala do outro, mas logo se desconecta. Momentos como esse tornaram-se mais evidentes em situações que envolviam dificuldades para executar tarefas motoras, atender a demandas por fala oralizada, quando a criança não se interessava pela brincadeira ou atividade desenvolvida ou quando seus apelos não eram correspondidos. $\mathrm{Na}$ cena 4 , C. olha, sorri e toca seu interlocutor, mas um impasse comunicativo se sobrepõe às suas solicitações e ele desiste.

\section{Cena enunciativa 4:}

A pesquisadora (P.) se aproxima da criança que está sentada à mesa em um momento de brincadeira livre. (Abaixo: SI é segmento ininteligível)

(37) P: SI (fala algo com C.)

(38) C: (olha para a pesquisadora, toca na mão e aponta discretamente para algo em cima da mesa)

(39) P: SI (não entende o pedido da criança)

(40) C: (observa os colegas)

P: (observa C.)

(41) C: (volta-se para a pesquisadora, olha, sorri e toca na pesquisadora novamente)

(42) P: o que é que você quer?

(43) C: (aponta para algo em cima da mesa sorrindo)

(44) P: (a pesquisadora aponta para as bolinhas azuis que estão em cima da mesa, ao lado da criança)

(45) C: (a criança fica com o olhar distante) 
Ao longo da análise dos dados, foi possível observar C. tornando-se mais participativo e convocando o outro no diálogo. Essa posição foi efeito do modo como as profissionais passaram a escutar e falar com a criança. É digno de nota, apesar de poucos episódios observados pela pesquisadora, a presença de vocalizações para chamar a atenção dos colegas e professoras. Em alguns momentos, a criança chega a falar "tia" para se referir à auxiliar de desenvolvimento infantil (ADI), à professora e à pesquisadora. Na cena abaixo, C. está brincando sozinho, quando pega uma peça do brinquedo e ergue os braços olhando para os colegas. Naquele momento, "tia" era dirigido à ADI, como se pedisse ajuda para o que estava tentando dizer aos seus colegas. Não obtendo sucesso no pedido, C. retorna a brincar sozinho e fica ali, mais uma vez, à deriva. A cena 5 ilustra a posição de um corpo que pede por interpretação.

\section{Cena enunciativa 5:}

C. está sentado à mesa junto com os colegas, com algumas peças de brinquedos de encaixe. Dois colegas que estão sentados ao seu lado, tentam interagir com a criança oferecendo peças do brinquedo. A ADI está ao seu lado, porém, estava envolvida com outras demandas.

(46) C: (pega uma peça de cor azul, ergue a mão e vocaliza) "eeeei"

(47) C: tiaaa (olha para os colegas segurando a peça que tem em mãos)

(48) C: tiaa (olhando para os colegas)

(49) C: (volta a brincar sozinho)

Ainda que a emergência da oralidade ocorra de maneira pontual, o corpo falante se faz presente em situações diversas. Isso ocorre de maneira mais forte na presença da música, quando são realizadas as atividades grupais em que todas as crianças cantam músicas infantis em conjunto. C., apesar de não cantar, apresenta movimentos intensos da boca e da língua e seus movimentos corporais são tomados pelo ritmo da canção. C. dança e canta, ainda que sem voz ou com vocalizações mínimas. Ele repete os movimentos dos colegas, mas também antecipa coreografias. Parece colado, especular ao movimento do outro, mas é toda uma cena que parece retornar com a canção (voz e gesto, no caso dele tentativas de gestos articulatórios e membros superiores), como pode ser visto na cena abaixo.

\section{Cena enunciativa 6:}

Todas as crianças estão sentadas em um semicírculo ("rodinha"), com a professora (A2) ao centro e C. ao seu lado esquerdo. A professora solicita que as crianças cantem uma canção para iniciar a atividade: "a dona aranba subiu pela parede..."

(50) C: (começa a sorrir de maneira intensa e a dançar o que parece uma coreografia compartilhada pelo grupo em outros momentos similares - chuva e sol, a aranha subindo pela parede. A boca de C. se movimenta bastante, há movimentação da língua e algumas vocalizações)

(51) A2: pronto, agora vamos cantar outra (começa a cantar a música da baleia)

(52) C: (observa os colegas cantando)

(53) A2: vamos cantar a do peixinho?

(54) C: (se anima com a música, faz a coreografia antecipando os movimentos, sorri bastante e apresenta movimentação da língua)

(55) A2: vai C., mergulha aí (faz o movimento do peixe embaixo da água)

(56) C: (olha para a colega ao lado e faz o mesmo movimento, colocando as mãos no nariz)

Já vimos em outros momentos que C. tem escuta para a fala que lhe é dirigida, mas ele parece ser profundamente afetado quando voz e movimento se aliam. É o que se pode ver na cena a seguir.

\section{Cena enunciativa 7:}

As crianças estão sentadas à mesa aguardando o almoço ficar pronto. A professora (A2) está sentada ao lado de C., brincando com a criança. (Abaixo: Cça - colega de turma) 
(57) Cça: (brinca com C. escondendo um pedaço da massa de modelar em uma das mãos)

(58) A2: ó pra cá C., advinha

(59) C: (olha, sorri e "bate" na mão do colega)

(60) Cça: (abre as mãos mostrando onde está a massa de modelar)

(61) A2: acertou (vibrando e batendo palmas para C.)

(62) C: (olha para o colega)

(63) Cça: (sorri para C.)

(64) A2: (conversa com as crianças sobre o comportamento)

(65) C: (imita sozinho a brincadeira que o colega fez e sorri, olhando para as próprias mãos)

Diversos são os modos de presença de C. nos diálogos, mas a forma como ele é enlaçado no jogo dialógico pela interpretação do outro faz diferença. Queremos dizer com isso que C. precisa da fala estruturante do outro para se sustentar como falante, isto é, de alguém que possa sustentá-lo na posição de falante, lendo seu modo de participação e dando continuidade ao diálogo.

\section{Cena enunciativa 8:}

A professora distribui para cada aluno uma folha de papel crepom e cada criança deve fazer pequenas bolas com o papel. C. está sentado à mesa e ao seu lado está a sua ADI (A1). A criança apresenta dificuldades para cortar pequenos pedaços de papel e fazer "bolinhas", apesar da boa movimentação do braço esquerdo.

(66) A1: pede um pedaço a ela para você ajudar (toca na criança para chamar a atenção e aponta para a colega que está ao lado de C.)

(67) C: (olha para a colega que está ao seu lado e com a mão solicita o que foi pedido)

(68) A1: (observa a criança)

(69) C: (amassa a "bolinha" na mesa, olha para câmera e sorri, depois ergue o braço e entrega a "bolinha" para a sua colega)

(70) Cça: (pega a bolinha na mão de C.)

(71) C: (observa os colegas)

A escuta para o corpo que fala permite, inclusive, que a oralidade compareça em certos momentos em resposta a fala que the foi dirigida. Quando questionado se já havia montado um brinquedo com as peças de encaixe, C. olha para a pesquisadora e vocaliza "ôô" (ver em 76) - um retorno imediato de fragmento sonoro da fala do outro (ver 77, fragmento em negrito), mas que vem com diferença na forma e na entonação, como resposta, ou seja, não se trata de mera reprodução, mas de repetição da fala do outro, que sempre envolve diferença e diz de uma presença, ainda que fugaz, do sujeito.

\section{Cena enunciativa 9:}

C. está sentado à mesa junto com os colegas. Todas as crianças continuam com brinquedos em mãos antes da professora iniciar a atividade do dia. Uma colega pede para filmar junto com a pesquisadora.

(71) C: (olha para a câmera após a colega sentar-se junto com a pesquisadora e filmar conjuntamente)

(72) Cça: oi C. (em fraca intensidade)

(73) C: (está brincando com umas das peças de brinquedo de montar e olha para a câmera)

(74) P: Oi C.

(75) C: (olha para a câmera sorri e ergue o braço esquerdo)

(76) P: já montou?

(77) C: (olha, movimenta a boca, sorri e vocaliza em tom afirmativo) ôô 


\section{DISCUSSÃO}

No presente trabalho, assumimos a complexidade envolvida ao tomar como objeto de estudo a linguagem. Como nos ensina a proposta interacionista em Aquisição de Linguagem, falas de crianças são resistentes a classificações homogeneizantes e a aquisição de linguagem não segue a linearidade prevista em etapas de desenvolvimento. (LEMOS, 2006) É por isso que a metodologia de estudo desse fenômeno não pode abrir mão de acolher o fato de que o funcionamento da linguagem envolve uma multiplicidade de efeitos sobre os quais nenhum falante tem controle. Segundo Lemos (1992, p. 128), a injunção à interpretação, embora não garanta a equivalência entre o enunciado da criança e a interpretação que é ofertada, mostra que a interação com o outro é condição necessária para a aquisição de linguagem, mas o outro é "discurso ou instância de funcionamento da língua constituída". O investigador deve, portanto, assumir um compromisso com a singularidade das manifestações e implicar-se quanto a sua condição de intérprete. (CARVALHO, 2013) Ele deve tentar escapar da armadilha de procurar na fala infantil, ou na sua ausência, sentidos, categorias e regras linguísticas projetadas a partir de seu saber sobre a língua. (CARVALHO, 2017)

Poucos são os estudos envolvendo crianças com lesões neurológicas que abordem a linguagem fora do escopo que a toma como função mental superior, reflexo direto do funcionamento cortical aplicado para fins comunicativos. Como apontam Santos, Catrini e Ferrite (2018, p.02), os estudos até então dedicados à linguagem de crianças com SCZV "têm como objetivo descrever habilidades, mapear atrasos no desenvolvimento, comparando-as com crianças consideradas "típicas'". A aplicação de testes de rastreamento do comportamento comunicativo impõe ao investigador uma posição que não permite o acolhimento da singularidade das manifestações linguísticas e dos efeitos do encontro com o outro na cena viva. (LIER-DEVITTO, 2004)

Quando falamos em crianças que vivenciam impasses em sua trajetória na direção de tornar-se falante, a clínica fonoaudiológica passa a ser convocada. Nessa área, grande parte dos estudos debatem, sob um viés organicista, questões relacionadas a alimentação, deglutição e articulação, bem como sobre a contenção de movimentos involuntários. Em casos graves, a ausência de oralidade parece fazer pesquisadores e clínicos subtenderem que esses sujeitos estão fora da linguagem, uma vez que gestos e vocalizações por vezes não são considerados como de natureza linguística, tampouco são considerados como uma tentativa de enlaçamento com o outro. (DUDAS e LIER-DEVITTO, 2016)

Em crianças com alterações neurológicas, a doença ocupa um status de maior destaque, reduzindo o sujeito a um desarranjo motor e cognitivo. Esse ponto de vista traz impactos no modo como a criança é posta no laço com o outro que promove o enlaçamento com o Outro - a captura pela linguagem, tão essencial para a emergência do corpo e do sujeito. Os resultados alcançados por nós colocaram em destaque a posição do outro frente crianças cuja lesão orgânica coloca em evidência um desajuste em relação ao que se considera como "típico", normal. Como destacamos, na avaliação de crianças com alterações neurológicas, na análise do material, muitas vezes, não se privilegia nem mesmo o posicionamento do corpo da criança para que ele seja colocado no lugar de um sujeito a quem se endereça a fala. Goodwin (2007) aponta para a importância do posicionamento dos corpos na organização da cena interativa e destaca a necessidade de construção de um alinhamento afetivo entre adulto e a criança ${ }^{5}$.

O corpo lesionado de $\mathrm{C}$. incide sobre o imaginário daqueles que estão em seu entorno. Por um lado, as crianças o nomeiam como bebê, ainda incapaz. Por outro, a prática pedagógica não consegue retirá-lo do campo da deficiência, ainda que sob a insígnia "especial". Especial, nesse caso, "é significante que lhe dá um lugar na cultura e indica já de início uma série de cuidados que esta criança deve receber e poderá ou não marcá-la como sujeito, portanto." (BRAUER, 1998, p. 59)

Surpreendente foi o questionamento de um dos colegas de turma de C.. Disse ele: "eu também sou especial". Não se pode mesmo apagar diferenças incontornáveis a partir da menção a portadores de necessidades especiais. No entanto, as cenas analisadas e o pedido de ajuda demandado pela professora à pesquisadora mostram que esse atravessamento coloca impasses no modo como o outro interage e interpreta a criança. O significante "bebê especial"

5. O autor desenvolve uma discussão importante que, mesmo a partir de uma perspectiva teórica distinta daquela que sustenta o ponto de vista deste trabalho, ilumina a discussão sobre o papel do posicionamento corporal no enlaçamento entre participantes de uma cena enunciativa. Seu artigo aborda uma situação distinta daquela aqui discutida. No caso de Goodwin (2007), a cena envolve a interação paifilha na realização da lição de casa, cena que envolve a construção de um alinhamento afetivo e cognitivo especial. Ele conclui que: "tais fenômenos lançam luz sobre uma variedade de diferentes tipos de posturas epistêmicas, morais e afetivas que são centrais para a organização da cognição e da ação, e como os participantes se constituem como tipos específicos de atores sociais e morais em meio as atividades mundanas que constituem a vida familiar cotidiana". (GOODWIN, 2007, p. 53, tradução nossa) 
marca diferentes interpretações que o outro pode ofertar e as dificuldades que podem ser encontradas na trajetória de constituição de C. como sujeito falante e em seu processo de escolarização.

De fato, a inclusão escolar de crianças com deficiências por si só é um grande problema na maioria das escolas, sejam públicas ou privadas. Em se tratando de crianças que não oralizam, os entraves são ainda maiores. O impasse já se inicia no imaginário coletivo de que se a criança não "fala", não entende a fala que lhe é dirigida. Quando, na verdade, esses sujeitos não são entendidos pelo outro. (DUDAS, 2016) Como demonstrado nos segmentos dialógicos analisados aqui, o corpo de C. convoca o outro para a interpretação durante os diálogos. Poder escutá-lo ou antecipá-lo parece essencial nesse caso.

Não há uma relação dual, porque nela está incluído um terceiro elemento que não deve ser negligenciado - há o funcionamento da língua ou, dito de outro modo, há um funcionamento estrutural que movimenta o jogo combinatório das unidades significantes presentes na cadeia da fala do outro e que permeiam sua possibilidade de interpretação da fala da criança. Interpretação aí é restrição e ressignificação, uma vez que o outro atribui forma e significado às produções da criança que são, muitas vezes, enigmáticas (FONSECA, 2002; BELTRÃO e CARVALHO, 2008). Assim, a interpretação ocorre com a tomada de decisão na língua e frente à fala e ao corpo da criança. A interpretação, portanto, exige do investigador relação com a língua e com a fala da criança. (SPINA-DE-CARVALHO, 2003)

No campo da clínica, LierDeVitto e Arantes (1998) sinalizam a necessidade da interpretação ser estruturante, possibilitando ao sujeito um vir a ser falante. Vale dizer que no diálogo entre a Clínica de Linguagem e a proposta interacionista de Lemos $(1992,2002,2006)$, destaca-se que a interpretação do outro incide não somente sobre a fala, mas também sobre o corpo da criança, que é atravessado pelo linguístico "na transformação: 'do ouvir para o escutar e para o escutar-se (LEMOS, 1995 apud FONSECA, 2002, p. 189). É nesse sentido que Lemos define a aquisição de linguagem como processo de subjetivação no qual a criança é capturada pelo funcionamento linguístico-discursivo. (OLIVEIRA e CATRINI, 2017)

Trata-se mesmo do corpo pulsional, tal como propõe a Psicanálise, aquele que necessita de interpretação, emergindo na demanda e no desejo e que não vai necessariamente ao encontro do corpo orgânico. O corpo de que se fala aqui é aquele estruturado pela linguagem. (LEMOS, 2002; CARVALHO, 2009) Oliveira e CATRINI (2017) referem que é no campo da aquisição da linguagem que o corpo se torna uma questão. No entanto, também sinalizam que no campo da clínica as manifestações sintomáticas de fala/escrita colocam em evidência o corpo e a sua íntima relação com a linguagem. É isso o que testemunham os trabalhos de pesquisadores ligados à Clínica de Linguagem. Em consonância com o modelo interacionista de Cláudia de Lemos, os trabalhos desse grupo de pesquisa partem do pressuposto de que o corpo do ser que fala não é redutível a seu substrato orgânico. Exemplares e muito próximos do que se observa em crianças com a SCVZ, estão os relatos de Vasconcellos $(1999,2006,2010)$ ao mobilizar discussões teórico-clínicas a partir de inquietações produzidas pelas limitações orgânicas impostas pela Paralisia Cerebral (PC).

Vasconcellos $(2006,2010,2018)$ conclui que os impedimentos orgânicos não são capazes de barrar os olhares e gestos da criança no diálogo com o outro. Os achados da autora vão ao encontro do que foi obtido nessa pesquisa. C. a todo momento convoca o outro com olhares, sorrisos e o toque. Segundo Bergès (2008), para que haja a emergência do corpo, este precisa ser emoldurado, capturado pelos ritmos e pelo olhar do outro, ou seja, é pelos significantes que o outro circunscreverá os gestos e os olhares da criança, que mesmo um tanto "presa" à sua condição orgânica poderá emergir no diálogo. (CATRINI, LIER-DEVITTO e ARANTES, 2015)

Ainda que nem sempre as respostas de $\mathrm{C}$. fossem as esperadas, as intervenções da pesquisadora fizeram surgir o inusitado reconhecimento de que a despeito da lesão orgânica, C. podia escutar o que lhe era dito e seu corpo podia falar. Além disso, a possibilidade de adotar mecanismos de comunicação suplementar e alternativa (CSA), sugerida em resposta à demanda da professora por acessar conhecimentos pedagógicos de C., permitiu que o outro se aproximasse da criança em sua singularidade e heterogeneidade. A possibilidade do encontro de falas entre o outro (professor, terapeuta e/ou cuidador) e a criança é resultante do empréstimo do corpo e da voz deste outro, produzindo efeitos na linguagem e no corpo falante desses sujeitos marcados pela lesão orgânica. (VASCONCELLOS, 2018) No estudo de caso aqui apresentado, "empréstimos" do corpo e da voz do outro possibilitaram que a criança pudesse falar. Com isso, observaram-se mudanças de sua posição em relação ao outro, de um sujeito passivo no diálogo para um sujeito mais participativo. Foi preciso que alguém, um outro instrumentalizado por uma teoria de linguagem, pudesse escutar um corpo falante e convocá-lo a integrar à cena dialógica, não como um "bebê", mas como alguém, que apesar de seus limites, pode ocupar um lugar, uma posição nas cenas enunciativas 
Nesse sentido, destaca-se a posição da pesquisadora durante a coleta dos dados no presente trabalho. Enquanto fonoaudióloga, mobilizada pela formação em Clínica de Linguagem, e por assumir observação participante enquanto investigadora, pôde intervir na cena viva, o que a aproximou bastante da posição do clínico. Note-se que há uma não coincidência entre a posição do clínico e a posição do investigador, pois enquanto o clínico sustenta a terapêutica, o cientista lida com o corpus, com um recorte da cena vivida pelo clínico e não tem possibilidades de intervenções em ato (LIER-DEVITTO, 2004)

O investigador faz apagamentos radicais da fala e do corpo da criança, inclusive durante as análises de dados. É certo que o desejo do investigador se inclui nos significantes da criança, isso porque ao escutar a fala de uma criança o investigador se escutaria nessa fala, nos pontos onde ele (a sua subjetividade) se refletiria. O desejo do investigador é, portanto, surpreendido pelas produções infantis que podem fugir à interpretação ou atributos de sentidos que pertenciam ao pesquisador. Nesse sentido, pode-se afirmar que o investigador está no campo do saber e do não-saber. (CARVALHO, 2009) Na clínica, o estar entre o saber e não saber sustenta-se em uma relação de transferência ${ }^{6}$ tocada diretamente pela presença do corpo que fala. Ao assumir uma posição próxima a do clínico, a pesquisadora pôde apontar um caminho para uma mudança na posição das profissionais da educação em relação a C., foi possível abrir espaço para que ele pudesse ocupar posição no grupo em que está inserido.

\section{CONCLUSÃO}

Neste trabalho, nosso objetivo foi refletir sobre a linguagem e a dimensão do corpo em crianças com lesões neurológicas associadas a SCZV a partir da análise de situações dialógicas ocorridas no espaço escolar, o que envolveu o encontro com as particularidades desse espaço. Evidenciamos a presença de um sujeito que, mesmo sob restrições impostas pela perturbação do funcionamento orgânico, pedia por interpretação e transbordava os efeitos da incidência da linguagem sobre o corpo em olhares, choro, gestos e fragmentos de oralidade.

Quando a pesquisadora adentra o espaço escolar, ela tem seu corpo marcado pela teorização da Clínica de Linguagem e da Psicanálise. É nessa posição que ela deixa-se afetar tanto por C. quanto pelo pedido de ajuda das profissionais de educação no que diz respeito à possibilidade "comunicativa" da criança. Nesse encontro, o compromisso com a fala e o falante levou irremediavelmente à escuta da pesquisadora para o corpo falante, uma vez que a ausência ou redução de uma fala oralmente articulada não apagou a presença de "olbares" e "gestos" da criança dirigidos ao outro.

Podemos afirmar que ao reconhecer o atravessamento da linguagem no corpo, a observação participante permitiu com que uma ética fosse transmitida. Testemunhamos, assim, um encontro interprofissional e suas potencialidades enquanto prática transformadora em direção ao cuidado integral para crianças com deficiência.

Nesse sentido, gostaríamos de destacar que, ainda que de maneira distinta do padrão idealizado, C. interagia e transitava em diferentes posições enunciativas, denotando que linguagem não se resume à comunicação e à enunciação oral. Acreditamos que essa é uma contribuição efetiva do presente trabalho, pois aponta para a importância de ampliar e transformar o olhar e a escuta destinados às crianças vítimas de SCZV nas diferentes esferas de cuidado a elas destinadas. Além disso, possibilita refletir sobre a necessidade do diálogo entre os campos da educação e da saúde, no que tange, a educação inclusiva de crianças com vulnerabilidades comunicativas.

\section{REFERÊNCIAS}

ALVES, L. V.; PAREDES, C. E.; SILVA, G. C.; MELLO, J. G.; ALVES, J.G. (2018). Neurodevelopment of 24 children born in Brazil with congenital Zika syndrome in 2015: a case series study. BMJ Open. v.8, n.7, p.1-5. Disponível em: http:// bmjopen.bmj.com/ Acesso em: 14 abril 2019.

ANDRADE, L. M (2003). Ouvir e escutar na constituição na clínica de linguagem. Tese de Doutorado em Linguística. Linguística Aplicada e Estudos da Linguagem, PUC, São Paulo.

6. Em Psicanálise, transferência é termo que diz de um deslocamento da realidade ou do inconsciente do analisante para a figura do analista. Segundo Lacan, o que se transfere para o clínico é um saber que se supõe que ele tenha. Para um maior esclarecimento a respeito do conceito de transferência no campo da clínica, indicamos o trabalho de Tesser (2012). 
ANDRADE, L. M. (2005). Considerações sobre a escuta na clínica de linguagem. Cadernos de Estudos Linguísticos. v. 7, n. 1 e 2, p. 167-174.

ARANTES, L. M. (2001). Diagnóstico e clínica de linguagem. Tese de Doutorado em Linguística. Linguística Aplicada e Estudos da Linguagem, PUC, São Paulo.

ARANTES, L. M. (2005). Sobre os efeitos do interacionismo no diagnóstico de linguagem. Cadernos de Estudos de Linguísticos. v. 47, n.1, p. 151-157.

ARANTES, L. M. (2006). Sobre a instância diagnóstica na clínica de linguagem. In: Lier-DeVitto M. F.; Arantes, L. M. (org.) Aquisição, Patologias e Clínica de Linguagem. São Paulo: Editora PUC SP, p. 315-329.

ARANTES, L. M. (2009). Diagnóstico de linguagem: sobre os efeitos das falas sintomáticas. In: Simpósio Nacional de Letras e Linguística II Simpósio Internacional de Letras e Linguística, Universidade Federal de Uberlândia. Disponível em: http:// www.ileel.ufu.br/anaisdosilel/wp-content/uploads/2014/04/silel2009_gt_lg23_artigo_7.pdf. Acesso em: 22 abril 2021.

ARAÚJO, T. V. B.; RODRIGUES, L.C.; XIMENES, R.A.A.; MIRANDA-FILHO, D.B.; MONTARROYOS, U.R.; MELO, A.P.L. et. al. (2016). Association between Zika virus infection and microcephaly in Brazil, January to May, 2016: preliminary report of a case-control study. The Lancet. v.16, n.12, p.1356-1363 Disponível em: http://dx.doi.org/10.1016/ S1473-3099(16)30318-8. Acesso em: 14 abril 2019

BAYLEY, N. (2006). Bayley Scales of Infant and Toddler Development. (3rd ed.). San Antonio: The Psychological Corporation.

BERGÉS, J. (2008). O corpo na Neurologia e na Psicanálise: lições clínicas de um psicanalista de crianças. Porto Alegre: Editora CMC.

BELTRAO, F. R.; CARVALHO, G. M. (2008). A singularidade do papel do outro na aquisição de linguagem de crianças abrigadas. Psicol. teor. Prat. v. 10, n. 1, p. 79-94.

BRASIL, Ministério da Saúde. (2019). Síndrome Congênita associada à infecção pelo Vírus Zika: Situação epidemiológica, ações desenvolvidas e desafios de 2015 a 2019. Boletim Epidemiológico.

BRAUER, J. F. (1998). O sujeito e a deficiência. Estilos da clínica. v. 3, n. 5, p. 56-62.

CARVALHO, A et al. (2019). Clinical and neurodevelopmental features in children with cerebral palsy and probable congenital Zika. Brain Development. Disponível em: https://doi.org/10.1016/j.braindev.2019.03.005 Acesso em: 14 abril 2019

CARVALHO, G. M. (2006). Levantamento de questões sobre a fala da criança como objeto de estudo no campo da aquisição de linguagem. Intercâmbio. v. 1, p. 1-6.

CARVALHO, G. M. (2009). A singularidade da fala da criança e o estatuto do investigador da aquisição de linguagem. Intercâmbio. v. 1, p. $10-14$.

CARVALHO, G. M. (2013). O investigador e a teoria: uma questão no campo da aquisição de linguagem. Letras de Hoje. v. 48, p. $283-289$.

CARVALHO, G. M. (2017). Questões sobre o investigador da trajetória linguística da criança. Revista Intercâmbio. v. XXXIV, p. $58-70$.

CATRINI, M., LIER-DEVITTO, M. F.; ARANTES, L. M. (2015). Apraxias: considerações sobre o corpo e suas manifestações motoras inesperadas. Cadernos de Estudos Linguísticos. Disponível em: http://dx.doi.org/10.20396/cel.v57i2.8642396 Acessado em: 02 jun 2020

CATRINI, M.; LIER-DEVITTO, M. F. (2019). Apraxia de fala e atraso de linguagem: a complexidade do diagnóstico e tratamento em quadros sintomáticos de crianças. CODAS, v. 31, p. 1-6.

COSTELlO, A.; et al. (2016). Defining the syndrome associated with congenital Zika virus infection. Editorials Bull World Health Organ. Disponível em: http://dx.doi.org/10.2471/BLT.16.176990 Acesso em: 14 abril 2019 
DINIZ, D. (2007). Modelo social da deficiência. In: DINIZ, D. (org.). O que édeficiência?. São Paulo: Editora Brasiliense, p. 7-33.

DUDAS, T. L. (2009). Paralisia cerebral e institucionalização: efeitos subjetivos e clínica de linguagem. Tese de Mestrado em Linguística. Linguística Aplicada e Estudos da Linguagem, PUC, São Paulo.

DUDAS, T. L. (2016). Problemas de linguagem e descompasso na inclusão escolar. Tese de Doutorado em Linguística. Linguística Aplicada e Estudos da Linguagem, PUC, São Paulo.

DUDAS, T. L.; LIER-DEVITTO, M. F. (2016). Institucionalização de pessoas com paralisia cerebral: a difícil relação sujeito outro - linguagem. Linguística. v. 32-1, p. 9-23.

FONSECA, S. C. (2002). O afásico na clínica de linguagem. Tese de Doutorado em Linguística. Linguística Aplicada e Estudos da Linguagem, PUC SP, São Paulo.

FRANÇA, G. V. A.; Lavinia Schuler-Faccini 2, Wanderson K Oliveira 1, Claudio M P Henriques 1, Eduardo H Carmo 1, Vaneide D Pedi 1, Marília L Nunes 1, Marcia C Castro 3, Suzanne Serruya 4, Mariângela F Silveira 5, Fernando C Barros 6, Cesar G Victora (2016). Congenital Zika virus syndrome in Brazil: a case series of the first 1501 livebirths with complete investigation. The Lancet, v. 388, p. 891-897.

FRANKENBURG, W. K.; et. al. (1992). Denver II: training manual. Denver Developmental Materials. Edição: 2nd ed. Denver, USA.

GOODWIN, C. (2007). Participation, stance and affect in the organization of activities. Discourse Society. v. 18, p.53-73.

LEMOS, C. T. G. (1992). Los processos metafóricos y metonímicos como mecanismos de cambio. Substratum, v. 1, n. 1, p. 120130

LEMOS, C. T. G. (2002). Das vicissitudes da fala da criança e de sua investigação. Cadernos de Estudos Linguísticos, v. 42 , p. $41-70$.

LEMOS, C. T. G. (2006). Uma crítica (radical) à noção de desenvolvimento na aquisição de linguagem. In: Lier-DeVitto M. F.; Arantes, L. M. (org.) Aquisição, Patologias e Clínica de Linguagem. São Paulo: Editora PUC SP, p. 21-30.

LIER-DEVITTO, M. F. (2006). Sobre a posição do investigador e a do clínico frente a falas sintomáticas. Letras de Hoje, v. 39 , n. 3, p. $47-60$.

LIER-DEVITTO, M. F. (2005). Falas sintomáticas: um problema antigo, uma questão contemporânea. In: FREIRE, M; ABRHÃO, M.H.; BARCELOS, A.M. F. (orgs.). Linguística Aplicada e Contemporaneidade. Campinas: Pontes Editores, p. 317-327.

LIER-DEVITTO, M. F; ARANTES, L. M. (1998). Sobre os efeitos da fala da criança: da heterogeneidade desses efeitos. Letras de Hoje, v. 33 n. 2, p. 65-71.

LIER-DEVITTO, M. F; ARANTES, L. M. (2020). Incidências da novidade Saussureana no Interacionismo e na Clínica de Linguagem. Revista Estudos em Letras, v. 1, n. 1, p. 65-76.

LIER-DEVITTO, M. F.; EMENDABILI, M. (2015). Uma posição sobre a escuta na clínica de linguagem. Linguística. v.31, n. 2, p. 73-82. Disponível em: http://www.scielo.edu.uy/scielo.php? script=sci_arttext\&pid=S2079-312X2015000200006\&ln $\mathrm{g}=\mathrm{es} \& \mathrm{nrm}=$ iso Acesso em: 02 jun. 2020.

MINAYO, M. C. S. (2014). O desafio do conbecimento: pesquisa qualitativa em saúde. São Paulo: Editora Hucitec.

MIRANDA-FILHO DB, et al. (2016). Initial Description of the presumed congenital Zika syndrome. Am J Public Health. Disponível em: http://dx.doi.org/10.2105/AJPH.2016.303115 Acesso em: 14 abril 2019.

NASIO, J. D. (2001). Que é um caso?. In: NASIO, J. D. Os grandes casos de psicose. Rio de Janeiro: Editora Jorge Zahar, p. 9-32. 
MOORE, C. et al. (2017). Congenital Zika Syndrome: Characterizing the Pattern of Anomalies for Pediatric Healthcare Providers. JAMA Pediatr. v.131, n.3, p. 288-295. Disponível em: doi:10.1001/jamapediatrics.2016.3982 Acesso em: 14 abril 2019

NUNES, M. L.; KAMPFF, J. P. R; SADEH, A. (2012). BISQ Questionnaire for Infant Sleep Assessment: translation into Brazilian portuguese. Sleep Sci. v.5, n. 3, p.89-91.

OLIVEIRA, D.; CATRINI, M. (2017). Questões dobre o corpo na aquisição e na clínica de linguagem. Estudos Linguísticos e Literários. n. 57, p. 366-381.

ROSENBAUM P; et al. (2007). A report: The definition and classification of cerebral palsy April 2006. Dev Med Child Neurol. v.49, p. $8-14$

SANTOS, B. S.; CATRINI, M.; FERRITE, S. (2018). A necessidade de estudos linguísticos na compreensão do processo de aquisição de linguagem em crianças com a Síndrome Congênita do Zika Vírus. In: $21^{\circ}$ InPLA - Intercâmbio de Pesquisas em Linguística Aplicada, 2018, São Paulo. Caderno de resumos $21^{\circ}$ InPLA - Intercâmbio de Pesquisas em Linguística Aplicada, v. Único. p. 122-122.

SPINA-DE-CARVALHO, D. C. (2003). Clínica de Linguagem: algumas considerações sobre interpretação. Tese de Mestrado em Linguística. Linguística Aplicada e Estudos da Linguagem, PUC, São Paulo.

SQUIRES, J; et al. (2009). Ages \& Stages Questionnaires: a parent-completed child monitoring system. Baltimore: Editora Paul H. Brookes Publishing.

SAUSSURE, F. (1913). Curso de Linguística Geral. São Paulo: Editora Cultrix, edição 28, 4a reimpressão. 2012.

TESSER, E. (2012). O diálogo na Clínica de Linguagem: considerações sobre transferência e intersubjetividade. Doutorado em Linguística. Linguística Aplicada e Estudos da Linguagem, PUC, São Paulo.

VASCONCELLOS, R. (1999). Paralisia cerebral: a fala na escrita. Tese de Mestrado em Linguística. Linguística Aplicada e Estudos da Linguagem, PUC, São Paulo.

VASCONCELLOS, R. (2006). Fala, escuta, escrita: a relação sujeito-linguagem no caso de uma criança com paralisia cerebral que não oraliza. In: Lier-DeVitto M. F.; Arantes, L. M. (org.) Aquisição, Patologias e Clínica de Linguagem. São Paulo: EDUC, p. 289-311.

VASCONCELLOS, R. (2010). Organismo e sujeito: uma diferença sensível nas paralisias cerebrais. Tese de Doutorado em Linguística. Linguística Aplicada e Estudos da Linguagem, PUC, São Paulo.

VASCONCELLOS, R. (2018). Efeitos da clínica de linguagem em casos de sujeitos com paralisia cerebral. Revista de Estudos da Linguagem, v. 26, n. 1, p. 355-387.

WHEELER AC, VENTURA, C.V.; RIDENOUR, T.; TOTH,D.;NOBREGA, L.L.; DANTAS, L.C.S.S.; ROCHA, C.; BAILEY JR., D.B.; VENTURA, L.O. (2018) Skills attained by infants with congenital Zika syndrome: Pilot data from Brazil. PLoS ONE. Disponível em: https://doi.org/10.1371/journal.pone.0201495_Acesso em: 14 abril 2019

Recebido: 29/7/2020

Aceito: 24/5/2021

Publicado: 1/6/2021 